Article

\title{
Design and Experimental Verification of 400-W Class LED Driver with Cooperative Control Method for Two-Parallel Connected DC/DC Converters
}

\author{
Tomoharu Yada ${ }^{1}$, Yuta Katamoto ${ }^{2}$, Hiroaki Yamada ${ }^{2, *}$, Toshihiko Tanaka ${ }^{2}$, Masayuki Okamoto ${ }^{3}$ \\ and Tsuyoshi Hanamoto ${ }^{4}(\mathbb{D}$ \\ 1 New Japan Radio Co., Ltd., 3-10, Nihonbashi Yokoyama-cho, Chuo-ku, Tokyo 103-8456, Japan; \\ tyada@njr.co.jp \\ 2 Graduate School of Sciences and Technology for Innovation, Yamaguchi University, 2-16-1, Tokiwadai, \\ Ube city, Yamaguchi 755-8611, Japan; v010vk@yamaguchi-u.ac.jp (Y.K.); totanaka@yamaguchi-u.ac.jp (T.T.) \\ 3 Department of Electrical Engineering, National Institute of Technology, Ube College, 2-14-1, Tokiwadai, \\ Ube city, Yamaguchi 755-8555, Japan; mokamoto@ube-k.ac.jp \\ 4 Graduate School of Life Science and Systems Engineering, Kyushu Institute of Technology, 2-4, Hibikino, \\ Wakamatsu, Kitakyushu city, Fukuoka 808-0196, Japan; hanamoto@life.kyutech.ac.jp \\ * Correspondence: hiro-ymd@yamaguchi-u.ac.jp; Tel.: +81-836-85-9471
}

Received: 26 July 2018; Accepted: 23 August 2018; Published: 26 August 2018

\begin{abstract}
This paper deals with a design and experimental verification of 400-W class light-emitting diode (LED) driver with cooperative control method for two-parallel connected DC/DC converters. In the cooperative control method, one DC/DC converter is selected to supply the output current for the LED, based on the reference value of the LED current. Thus, the proposed cooperative-control strategy achieves wide dimming range operation. The discontinuous current conduction mode (DCM) operation improves the total harmonic distortion (THD) value on the AC side of the LED driver. The standard of Electrical Applications and Materials Safety Act in Japan has defined the flicker frequency and minimum optical output. The smoothing capacitors are designed by considering the power flow and LED current ripple for satisfying the standard. A prototype LED driver is constructed and tested. Experimental results demonstrate that a wide dimming operation range from 1 to $100 \%$ is achieved with a THD value less than $10 \%$ on the AC side, by the proposed control strategy. The authors compare the power conversion efficiency between $\mathrm{Si}$ - and $\mathrm{SiC}$-metal-oxide-semiconductor field-effect transistors (MOSFETs) based LED driver. The maximum power conversion efficiency by using $\mathrm{SiC}-M O S F E T s$ based LED driver is $91.4 \%$. Finally, the variable switching frequency method is proposed for improving the power conversion efficiency for a low LED current region.
\end{abstract}

Keywords: LED driver; wide dimming operation; single-stage; parallel-connected DC/DC converter topology; cooperative control

\section{Introduction}

The 21st Conference of the Parties (COP21) of the United Nations Framework Convention on Climate Change, in December 2015, offered to set in motion an ambitious cycle of improved climate and clean energy action [1]. The energy efficiencies of the industries, buildings and transport facilities must be increased. In the field of lighting fixtures, light-emitting diodes (LEDs) are widely used to reduce energy consumption. Moreover, since the adoption of the Minamata Convention on Mercury in October 2013 [2], LED floodlights have been superseding the mercury lamps. LEDs offer many advantages such as high luminance efficiency, long operating life and high-speed response for many applications [3]. Two-stage topology is the most popular topology for LED drivers above $100 \mathrm{~W}$ because 
it provides a high power factor and low total harmonic distortion on the source side [4,5]. However, the power conversion efficiency is low because the converters are connected in series. To overcome this problem, single-stage forward and flyback power factor correction (PFC) converters with one active element [6], and single-stage half-bridge LLC DC-DC resonant converters [7,8] have been proposed. However, these topologies have complicated circuits and control algorithms. An efficient driver topology has been proposed in which a rectifier circuit with a diode bridge provides the forward voltage for the LED and the flyback converter controls the LED current [9]. This topology provides high efficiency at a low cost. However, for LED floodlights, this imposes limitations on the dimming range because the LED forward voltage is close to the rectified voltage of the diode rectifier circuit. Jane et al. have proposed a circuit topology with two parallel-connected flyback converters to overcome these limitations [10]. This single-stage topology uses two AC/DC converters with the outputs connected in series. One AC/DC converter provides the LED forward voltage, while the other AC/DC converter controls the LED current. The inputs of the two AC/DC converters are connected in parallel. Thus, the power conversion efficiency in the single-stage topology is an improvement over the two-stage topology, although it imposes a constraint on the minimum on-time of the active elements when the LED current is low. The authors have proposed a cooperative control method for the LED driver, using a parallel-connected flyback converter [11]. In this method, two DC/DC converters are controlled individually in response to the reference value of the LED current. However, the controller must be complex in order to achieve power factor correction (PFC) control because the proposed system has been designed in the critical conduction mode.

The authors have proposed a novel cooperative control method for an LED driver with a wide dimming range [12]. In this control method, two DC/DC converters are controlled individually in response to the reference value of the LED current. The two DC/DC converters are driven in the discontinuous mode (DCM). Therefore, the controller can achieve PFC in a simple manner, and the switching frequency is fixed. A lower current can be achieved, as compared to [11], by this proposed method. However, the design method for the smoothing capacitors wasn't discussed in [12]. In addition, the Si-metal-oxide-semiconductor field-effect transistors (MOSFETs) have been used for DC/DC converters in [12]. As a result, the maximum power conversion efficiency was $90.5 \%$.

This paper deals with a design and experimental verification of 400-W class LED driver with a cooperative control method for two-parallel connected DC/DC converters. The standard of Electrical Applications and Materials Safety Act in Japan [13] has defined the flicker frequency and minimum optical output. The smoothing capacitors are designed by considering the power flow and LED current ripple for satisfying the standard. Digital computer simulations are performed using the PLECS software (Ver.4.1.8, Plexim, Zürich, Switzerland), to confirm the validity of the proposed method. A prototype LED driver is constructed and tested. The proposed LED driver reduces the minimum LED current by $90.7 \%$, compared to the conventional control method. Experimental results demonstrate that a wide dimming operation, from $1 \%$ to $100 \%$, can be achieved with a THD value less than $10 \%$ on the AC side, by the proposed control strategy. The linear dimming is confirmed by changing the reference LED current. From simulation and experimental results, the proposed LED driver can achieve stable operation. However, dynamic analysis is not conducted. In a future work, it would be important to examine the system for its stability. The maximum power conversion efficiency by using SiC-MOSFETs based LED driver is $91.4 \%$. Finally, the variable switching frequency method is proposed for improving the power conversion efficiency for low LED current region.

The main contributions of this paper are as follows:

- Design of the smoothing capacitor for satisfying the standard of Electrical Applications and Materials Safety Act in Japan,

- Dynamic response of the proposed LED driver when the reference LED current is changed,

- Comparison of power conversion efficiency between Si- and SiC-MOSFETs,

- Improvement of power conversion efficiency in low current range by the proposed variable switching frequency method. 


\section{Conventional Control Method}

In general, a high-brightness LED driver circuit of more than $150 \mathrm{~W}$ consists of two series-connected converters, which are a boost converter with a PFC controller and a DC/DC converter to control the LED current. However, the power conversion efficiency is poor.

To overcome this problem, Jane has proposed a circuit topology with two parallel-connected constant-voltage output converters and constant current output converters [10]. Figure 1 shows the power circuit diagram of the single-stage topology [11]. This single-stage topology has higher power conversion efficiency than the two-stage topology. As shown in Figures 2 and 3, one DC/DC converter provides the LED forward voltage, whlie another DC/DC converter controls the LED current. Moreover, both converters implement the PFC control. These two converters are connected in parallel at the input ports and in series at the output ports.

However, this topology cannot control low LED currents because of the constraint of minimum duty ratio. If the reference LED current is small, the output voltage of the DC/DC converter for LED current control must be small. In this particular case, the duty ratio of the DC/DC converter for LED current control must be small. This means that the turn-on time of the switching device must be less. Therefore, the switching device cannot control perfectly in this region.

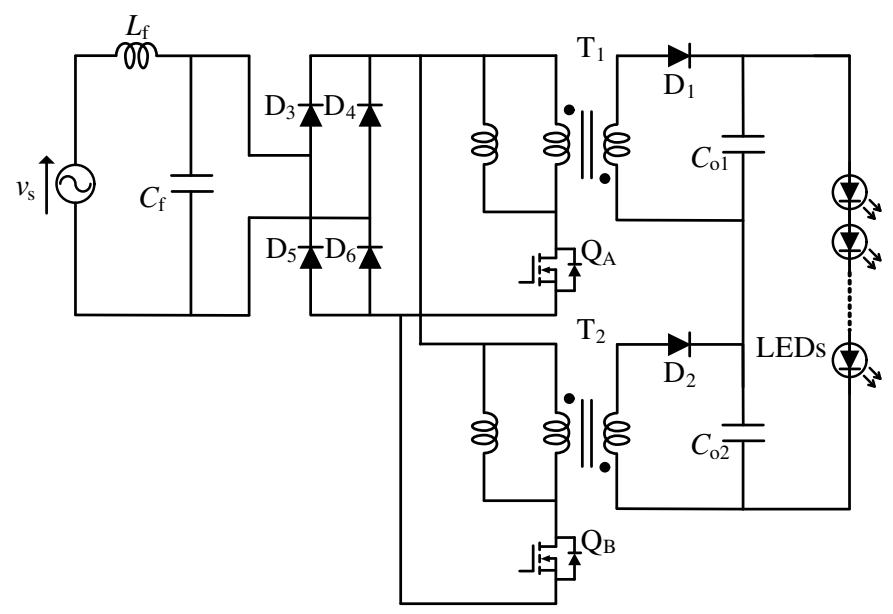

Figure 1. Previously proposed circuit diagram of light-emitting diode (LED) driver [4].

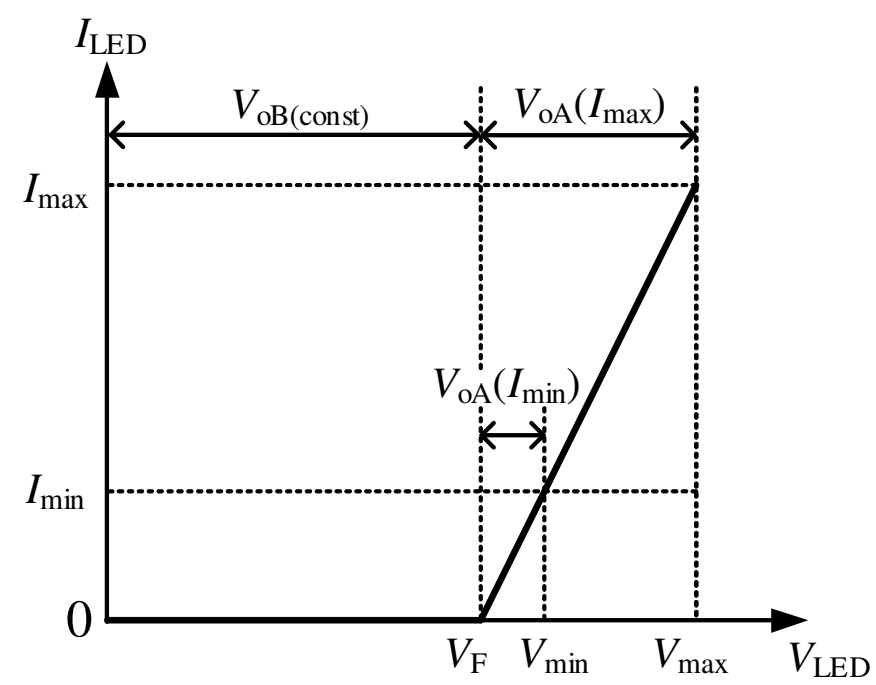

Figure 2. Output ranges of the converters with the conventional method. 


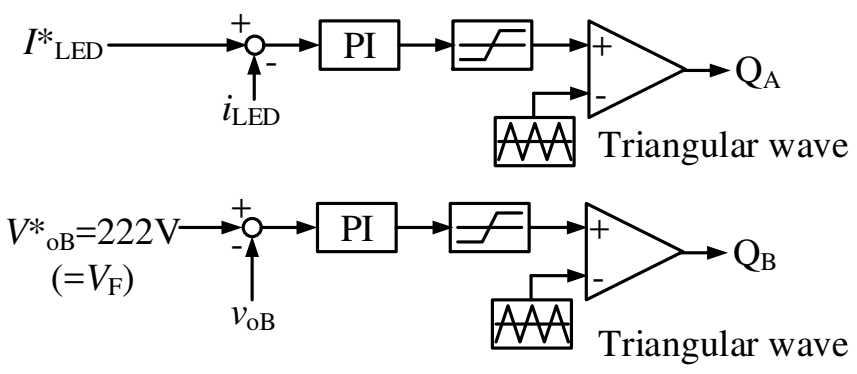

Figure 3. Control block of the proposed conventional method.

\section{System Configuration}

Figure 4 shows the power circuit diagram of the proposed LED driver. In this paper, we use an LED floodlight in which 72 LEDs are connected in series. The threshold voltage $V_{\mathrm{F}}$ is $222 \mathrm{~V}$ and the rated LED current is $1.5 \mathrm{~A}$. At the rated output, the buck-boost chopper outputs the threshold voltage of the LED lamp. This circuit is equivalent to a constant-current source, and it can control the forward current of the LED accurately. This circuit can operate in the linear dimming mode. The buck-boost chopper is not galvanic isolation so the insulation is inferior to the conventional circuit. However, galvanic isolation is not necessarily required in LED applications. By using a non-insulated buck-boost chopper, the transformer is replaced with an inductor so that it can deal with larger electric power as compared with a transformer of the same volume, so it can be miniaturized.

By operating in DCM, it can improve the power supply power factor using a simpler control system compared to [11]. In the steady state of the buck-boost chopper, the magnetizing inductance of the buck-boost converter, $L_{1}$, must satisfy the discontinuous current condition. The discontinuous current condition is given by

$$
R_{\mathrm{LED}} \geq \frac{2 L_{1} f_{\mathrm{SW}}}{\left(1-D_{\mathrm{QB}}\right)^{2}}
$$

where $R_{\mathrm{LED}}$ is the equivalent resistance of the LEDs, $f_{\mathrm{SW}}$ is the switching frequency, $D_{\mathrm{QB}}$ is the duty ratio of $Q_{\mathrm{B}}$. From Equation (1), $L_{1}$ must be $63 \mu \mathrm{H}$ for achieving the rated output operation. Similarly, the discontinuous current condition for the flyback converter in the steady state is given by

$$
D_{\mathrm{QA}}\left(1+\frac{n V_{\mathrm{Rec}-\max }}{V_{\mathrm{oA}}}\right) \leq 1,
$$

where $D_{\mathrm{QA}}$ is the duty ratio of $Q_{\mathrm{A}}$. $V_{\mathrm{Rec}-\max }$ is the maximum value of the input voltage of both converters, and $V_{\mathrm{oA}}$ is the output voltage of the fly-back converter. From Equation (2), $L_{\mathrm{p}}$ is $228 \mu \mathrm{H}$, $n=N_{\mathrm{p}} / N_{\mathrm{s}}$ is $9 / 24$. The value of the smoothing capacitors $C_{\mathrm{o} 1}$ and $C_{\mathrm{o} 2}$ are decided by the acceptable current ripple of the LED as per the standard of Electrical Appliances and Materials Safety Act in Japan [13].

By [13], when the flicker frequency is $100 \mathrm{~Hz}$ or more and less than $500 \mathrm{~Hz}$, the minimum optical output must be over $5 \%$ of the rated output. The flicker frequency of $I_{\text {LED }}$ is twice the AC source frequency, which is $50 \mathrm{~Hz}$ or $60 \mathrm{~Hz}$. Figure 5 shows the relationship between the LED current and LED illuminance. The blue dots are the measurement LED illuminance and the red line is the linear extrapolation. The LED illuminance shows saturation characteristics for the LED current. If we assume that the LED optical output is a linear function of $I_{L E D}$, the actual flicker characteristics are better than the standard value, and the maximum LED current $\left(I_{\mathrm{LED}-\max }\right)$ and the minimum LED current $\left(I_{\text {LED }-\min }\right)$ can be expressed by:

$$
\frac{I_{\mathrm{LED}-\min }}{I_{\mathrm{LED}-\max }}>\alpha,
$$


and, in this case, $\alpha=0.05$. Figure 6 shows the relationship between the LED current and LED voltage ripples. $\epsilon_{\mathrm{I}}$ and $\epsilon_{\mathrm{V}}$ are the LED current and voltage ripples, respectively. $I_{\mathrm{LED}-\max }$ and $I_{\mathrm{LED}-\min }$ can be expressed by:

$$
\begin{aligned}
I_{\mathrm{LED}-\max } & =\frac{\left(1+\epsilon_{\mathrm{V}}\right) V_{\mathrm{DC}}-V_{\mathrm{F}}}{R_{\mathrm{LED}}}, \\
I_{\mathrm{LED}-\min } & =\frac{\left(1-\epsilon_{\mathrm{V}}\right) V_{\mathrm{DC}}-V_{\mathrm{F}}}{R_{\mathrm{LED}}} .
\end{aligned}
$$

From Equations (3) and (4), $\epsilon_{\mathrm{V}}$ can be expressed by:

$$
\epsilon_{\mathrm{V}}=\frac{(1-\alpha)\left(V_{\mathrm{DC}}-V_{\mathrm{F}}\right)}{(1+\alpha) V_{\mathrm{DC}}}
$$

Figure 7 shows the relationship between the power flows and voltage ripple of the smoothing capacitor. $p_{\text {in }}$ is the input power of the smoothing capacitor and LED. $p_{\text {out }}$ is the output power of the LED. $p_{\mathrm{c}}$ is the inflow and outflow power of the smoothing capacitor. When output power is at a maximum, the output voltage $V_{\mathrm{DC}}$ is $272 \mathrm{~V}$ and $\epsilon_{\mathrm{V}}$ is the maximum value as 0.166 . Assuming the power factor is 1 , source voltage, current and input power can be expressed by:

$$
\begin{aligned}
v_{\mathrm{s}}(t) & =\sqrt{2} V_{\mathrm{rms}} \sin \left(2 \pi \frac{t}{T_{\mathrm{s}}}\right), \\
i_{\mathrm{S}}(t) & =\sqrt{2} I_{\mathrm{rms}} \sin \left(2 \pi \frac{t}{T_{\mathrm{s}}}\right), \\
p_{\mathrm{in}}(t) & =2 P \sin ^{2}\left(2 \pi \frac{t}{T_{\mathrm{s}}}\right),
\end{aligned}
$$

where $T_{\mathrm{s}}$ is the AC source voltage period and $P$ is $V_{\mathrm{rms}} I_{\mathrm{rms}}$.

Assuming the power conversion efficiency is $100 \%$, the power into and out of the smoothing capacitor $\Delta P_{\mathrm{C}}$ can be expressed by:

$$
\begin{aligned}
\Delta P_{\mathrm{C}} & =p_{\text {in }}(t)-P \\
& =2 P \sin ^{2}\left(2 \pi \frac{t}{T_{\mathrm{s}}}\right)-P .
\end{aligned}
$$

In addition, the energy into the smoothing capacitor $\Delta U_{C_{-} \text {in }}$ can be expressed by:

$$
\begin{aligned}
\Delta U_{C_{-} \text {in }} & =\int_{t_{0}}^{t_{0}+T_{\mathrm{s}} / 4}\left[2 P \sin ^{2}\left(2 \pi \frac{t}{T_{\mathrm{s}}}\right)-P\right] \\
& =P \frac{T_{\mathrm{s}}}{2 \pi} .
\end{aligned}
$$

Otherwise, $\Delta U_{C_{-} \text {in }}$ can be expressed with $\epsilon_{\mathrm{V}}$ by:

$$
\Delta U_{\mathrm{C}_{-} \text {in }}=\frac{1}{2} C_{\mathrm{o}}\left[\left\{\left(1+\epsilon_{\mathrm{V}}\right) V_{\mathrm{DC}}\right\}^{2}-\left\{\left(1-\epsilon_{\mathrm{V}}\right) V_{\mathrm{DC}}\right\}^{2}\right],
$$

where $C_{\mathrm{o}}$ is the combined smoothing capacitor of $C_{\mathrm{o} 1}$ and $C_{\mathrm{o} 2}$. From Equations (8) and (9),

$$
C_{\mathrm{o}}=\frac{P T_{\mathrm{S}}}{4 \pi \epsilon_{\mathrm{V}} V_{\mathrm{DC}}^{2}} .
$$

When the output power is the maximum as $408 \mathrm{~W}$ and $T_{\mathrm{s}}$ is $1 / 60 \mathrm{~Hz}, C_{\mathrm{o}}$ is $44.06 \mu \mathrm{F} . C_{\mathrm{o} 1}$ and $C_{\mathrm{o} 2}$ are series connection. Therefore, $C_{\mathrm{o}}$ can be expressed by: 


$$
C_{\mathrm{o}}=\frac{C_{\mathrm{o} 1} C_{\mathrm{o} 2}}{C_{\mathrm{o} 1}+C_{\mathrm{o} 2}} .
$$

Thus, $C_{\mathrm{o} 1}$ and $C_{\mathrm{o} 2}$ are $110 \mu \mathrm{F}$ in this paper. Table 1 indicates the circuit constants of the proposed LED driver.

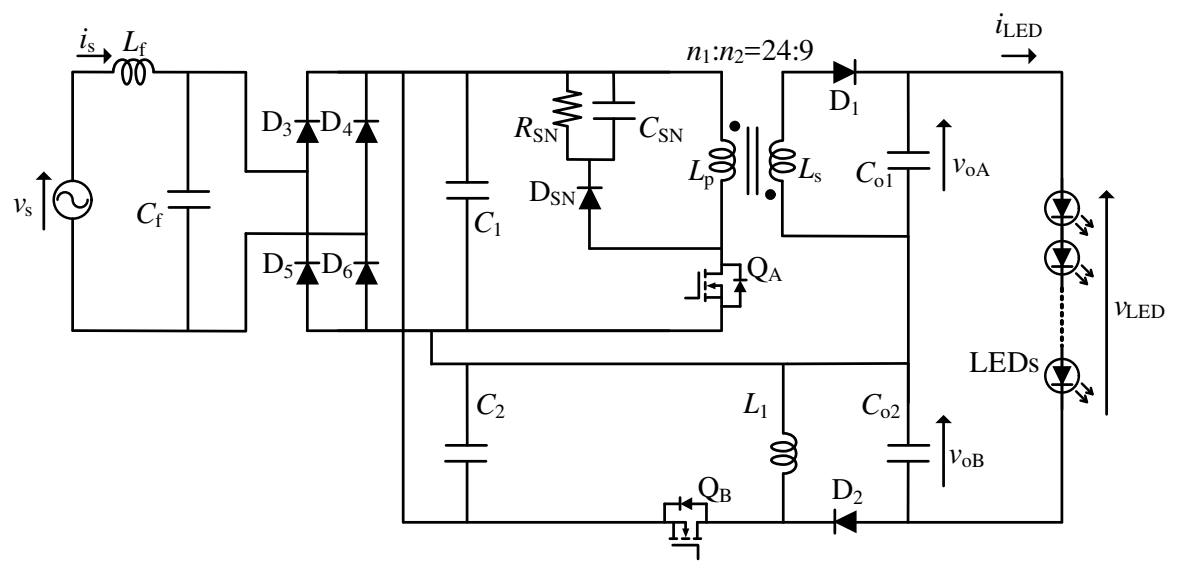

Figure 4. Power circuit diagram of the proposed LED driver.

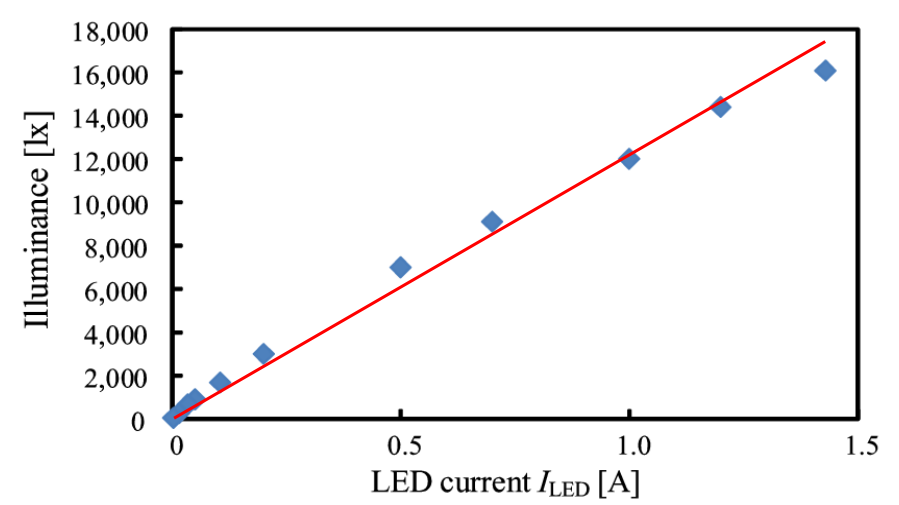

Figure 5. Relationship between the LED current and LED illuminance.

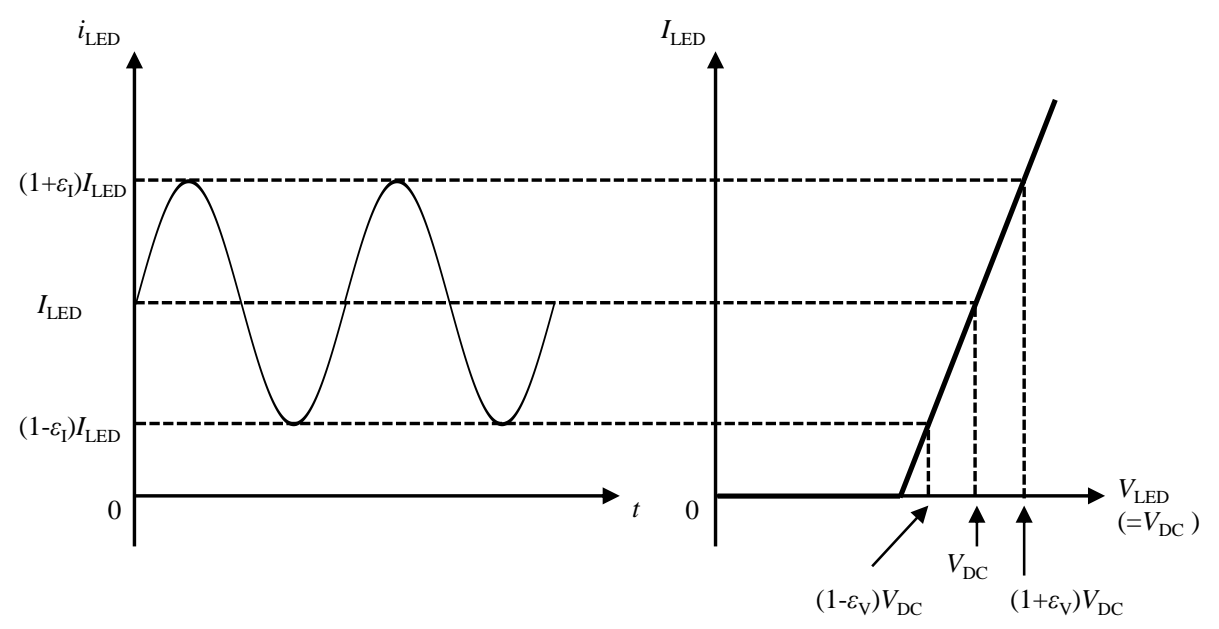

Figure 6. Relationship between the LED current and LED voltage ripples. 


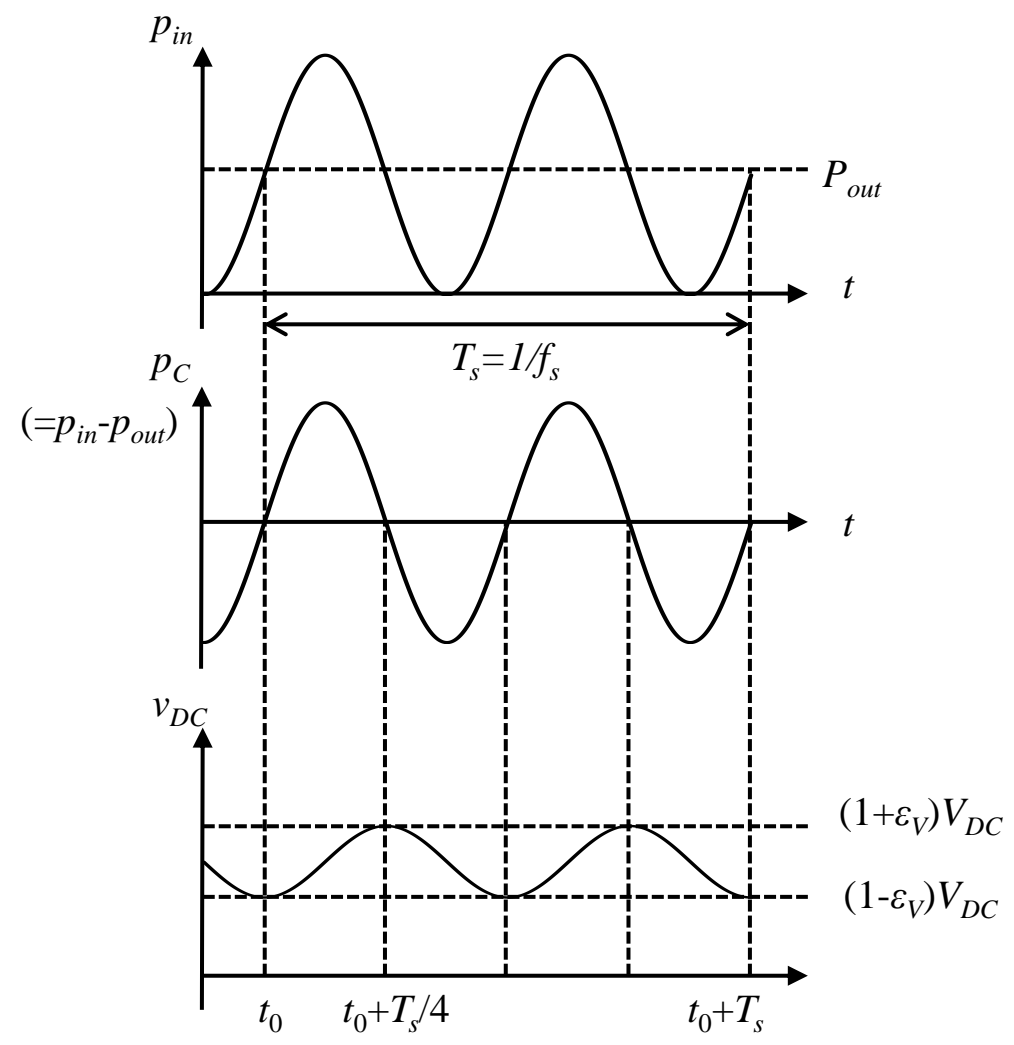

Figure 7. Relationship between the power flows and voltage ripple of the smoothing capacitor.

Table 1. Circuit constants of the proposed LED driver.

\begin{tabular}{ccc}
\hline Item & Symbol & Value \\
\hline AC source voltage & $V_{\mathrm{s}}$ & $100 \mathrm{Vrms}$ \\
Inductance of filter inductor & $L_{\mathrm{f}}$ & $265 \mu \mathrm{H}$ \\
Capacitance of filter capasitor & $C_{\mathrm{f}}$ & $0.1 \mu \mathrm{F}$ \\
Capacitance & $C_{1}, C_{2}$ & $0.1 \mu \mathrm{F}, 0.1 \mu \mathrm{F}$ \\
Capacitance & $C_{\mathrm{o} 1}, C_{\mathrm{o} 2}$ & $110 \mu \mathrm{F}, 110 \mu \mathrm{F}$ \\
Buck-boost inductance & $L_{1}$ & $69 \mu \mathrm{H}$ \\
Turn ratio & $N_{1}: N_{2}$ & $24: 9$ \\
Inductance of primary side & $L_{\mathrm{p}}$ & $228 \mu \mathrm{H}$ \\
Snubber resistance & $R_{\mathrm{SN}}$ & $23.5 \mathrm{k} \Omega$ \\
Snubber Capacitance & $C_{\mathrm{SN}}$ & $1 \mathrm{nF}$ \\
Switching frequency & $f_{\mathrm{sw}}$ & $50 \mathrm{kHz}$ \\
\hline
\end{tabular}

\section{Proposed Cooperative Control Method}

The authors have proposed a cooperative control method for an LED driver with a wide a dimming range to overcome the technical issues of the conventional control method [11]. Figure 8 shows the output ranges of the converters with the proposed cooperative control method. In this control method, the output voltage $V_{\mathrm{oB}}$ of the buck-boost converter, which is used for voltage control, changes in response to the LED current. Therefore, $Q_{\mathrm{A}}$ can operate in the stable region. The proposed control method makes it possible for the LED driver to control LED currents as low as $15 \mathrm{~mA}$.

The output voltages of the fly-back converter $V_{\mathrm{oA}}$ and the buck-boost chopper $V_{\mathrm{oB}}$ are given by

$$
V_{\mathrm{OA}}=T_{\mathrm{on}(\mathrm{QA})} V_{\operatorname{Rec}} \sqrt{\frac{\eta R_{\mathrm{LED}} f_{\mathrm{sw}}}{2 L_{\mathrm{p}}}}
$$




$$
V_{\mathrm{oB}}=V_{\mathrm{LED}}-T_{\mathrm{on}(\mathrm{QA})} V_{\mathrm{Rec}} \sqrt{\frac{\eta R_{\mathrm{LED}} f_{\mathrm{sw}}}{2 L_{\mathrm{p}}}}
$$

where $V_{\mathrm{LED}}$ is the applied voltage of the LED and $\eta$ is the power-conversion efficiency of the fly-back converter. In general, the on-interval of the switching device must be more than 10 times the turn-on time of the switching device, for stable gate driving. In this paper, we use the MOSFETs (STF20NM65N). From its data sheet, the minimum value of the on-time is determined to $300 \mathrm{~ns}$. The minimum value of the LED current in the conventional control method is $161 \mathrm{~mA}$ under this condition.

It is assumed that the on interval $T_{\mathrm{on}(\mathrm{QA})}$ is over $300 \mathrm{~ns}$ when the output current is $1 \%$ of the rated LED current. Under these conditions, the output voltage of the fly-back converter is determined to be $V_{\mathrm{oA}}=21.5 \mathrm{~V}$ from Equation (13). Assuming $V_{\mathrm{OA}}=30 \mathrm{~V}$, the output voltage of the buck-boost chopper is determined as $V_{\mathrm{oB}}=197 \mathrm{~V}$ from Equation (12). The reference value of the buck-boost converter $V_{\mathrm{oB}}^{*}$ changes in response to the reference value of $I_{\mathrm{LED}}^{*}$. From Equation (13), the reference value $V_{\mathrm{oB}}^{*}$ is given as follows:

$$
V_{\mathrm{oB}}^{*}\left(I_{\mathrm{LED}}^{*}\right)=19.9 I_{\mathrm{LED}}^{*}+192 .
$$

Figure 9 shows the control block of the proposed cooperative control method.

In this paper, the AC source voltage is 100 Vrms. From Equation (12), if the AC source voltage is higher, $T_{\mathrm{on}(\mathrm{QA})}$ is under $300 \mathrm{~ns}$ when the output current is $1 \%$ of the rated LED current. When the AC source voltage is changed, the system parameters need to be redesigned.

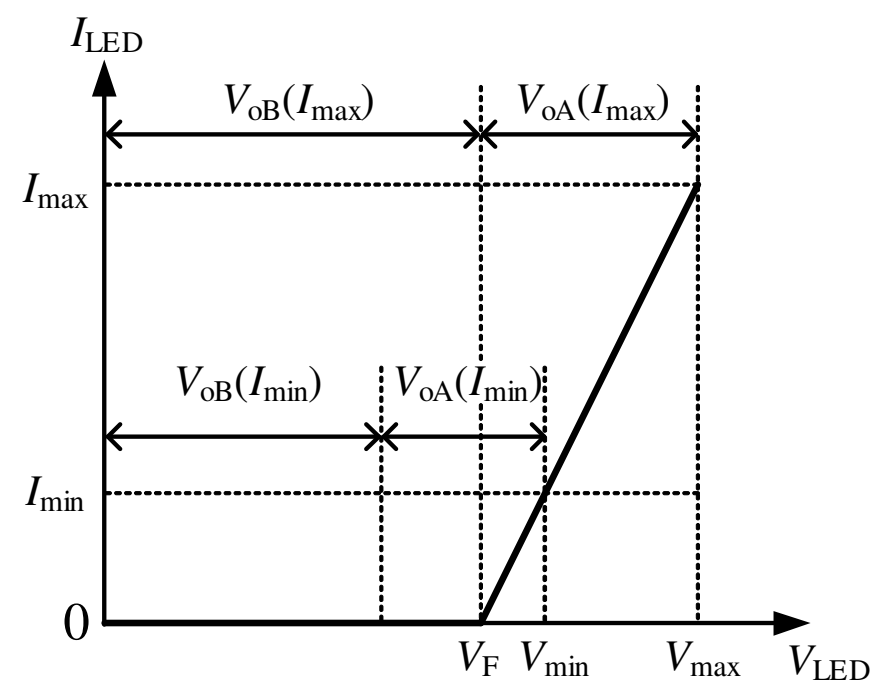

Figure 8. Output ranges of the converters with the proposed cooperative control method.

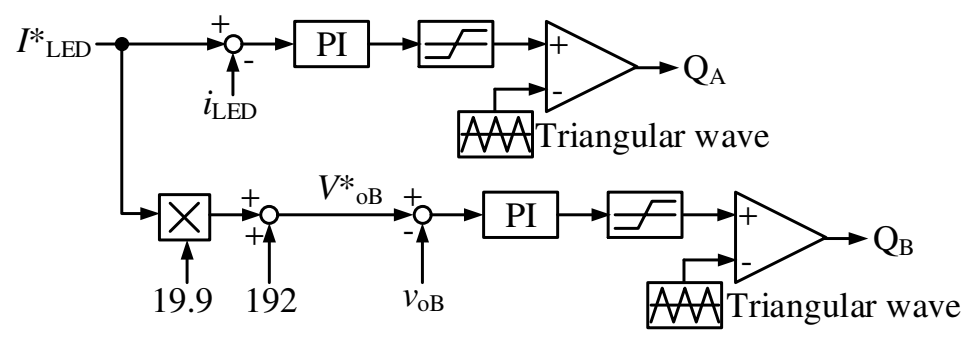

Figure 9. Control block of the proposed cooperative control method. 


\section{Simulation Results}

Digital computer simulations were performed using the PLECS software, to confirm the validity of the proposed method. The LED floodlight, which was modeled by the linear diode, included the threshold voltage $V_{\mathrm{F}}$ and the on-resistance on the simulator.

Figure 10 shows the simulation results of the proposed cooperative control method when the reference LED current $I_{\mathrm{LED}}^{*}$ is $1.5 \mathrm{~A} . v_{\mathrm{S}}$ is the source voltage, $i_{\mathrm{S}}$ is the source current, $V_{\mathrm{oB}}$ is the output voltage of the buck-boost chopper, and $I_{\mathrm{LED}}$ is the LED current. From Figure 10, it can be observed that the average LED current agrees with the reference LED current of $1.5 \mathrm{~A}$. In addition, $i_{\mathrm{s}}$ is nearly sinusoidal and the power factor is 0.99 .

Figure 11 shows the LED current and the output voltage of the buck-boost chopper for the reference output current $I_{\mathrm{LED}}^{*}$. The solid line is the reference value $V_{\mathrm{oB}}^{*}$ calculated from Equation (14). In Figure 11, the red and blue dots represent the simulation results. From Figure 11, we can observe that the outputs of both converters agree with the reference values.

Figure 12 shows the simulation result of the transient response characteristic for the reference LED current $I_{\mathrm{LED}}^{*} \cdot I_{\mathrm{LED}}^{*}$ is changed from the minimum reference LED current $15 \mathrm{~mA}$ to the maximum $1.5 \mathrm{~A}$ in about $0.1 \mathrm{~s}$. The output voltage of the buck-boost chopper $V_{\mathrm{oB}}$ and the output LED current are changed stably from the minimum value to the maximum in about $0.5 \mathrm{~s}$.

Figures 13 and 14 show the Fast Fourier Transform (FFT) analysis results of $i_{\mathrm{s}}$. From these figures, it can be inferred that the LED driver with the proposed cooperative control method can satisfy the conditions of IEC61000-3-2.

Figure 15 shows the simulated waveforms of the drain currents $i_{\mathrm{ds}(\mathrm{QA})}$ and $i_{\mathrm{ds}(\mathrm{QB})}$ for a reference LED current $I_{\mathrm{LED}}^{*}$ of $15 \mathrm{~mA}$. From these waveforms, it can be observed that the on-intervals of $Q_{\mathrm{A}}$ and $Q_{B}$ are always more than $300 \mathrm{~ns}$.
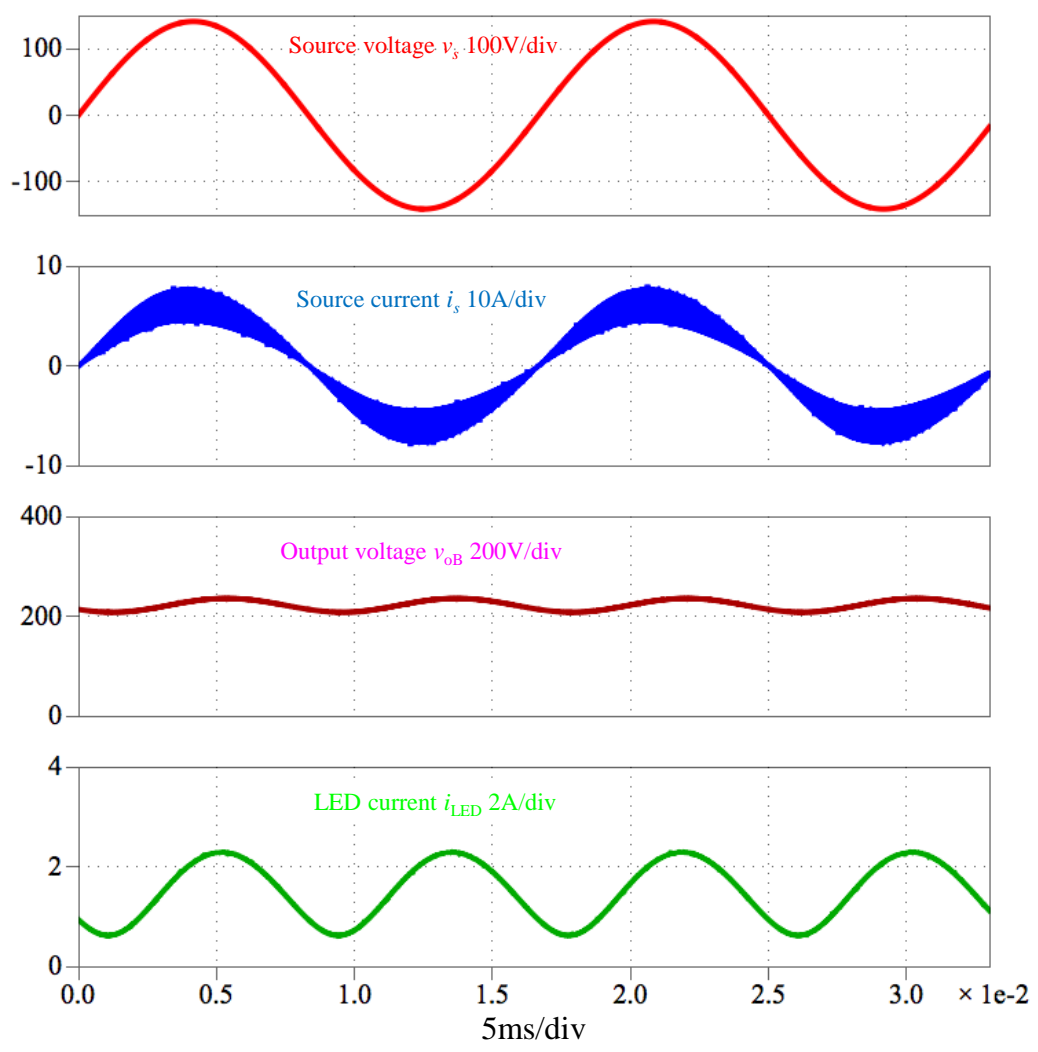

Figure 10. Simulation results of the proposed cooperative control method when the reference LED current $I_{\text {LED }}^{*}$ is $1.5 \mathrm{~A}$. 


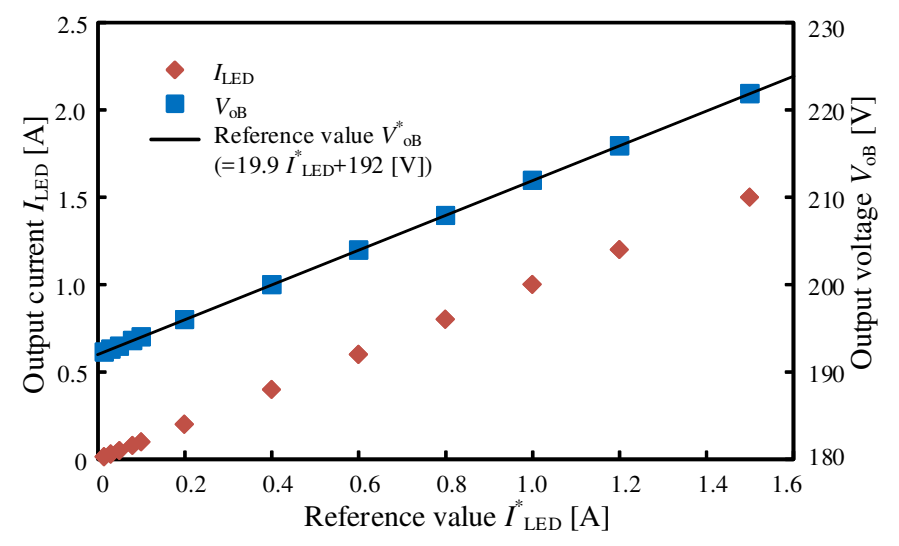

Figure 11. Simulation results of the output current $I_{\mathrm{LED}}$ and voltage $V_{\mathrm{oB}}$ for the reference LED current $I_{\text {LED }}^{*}$
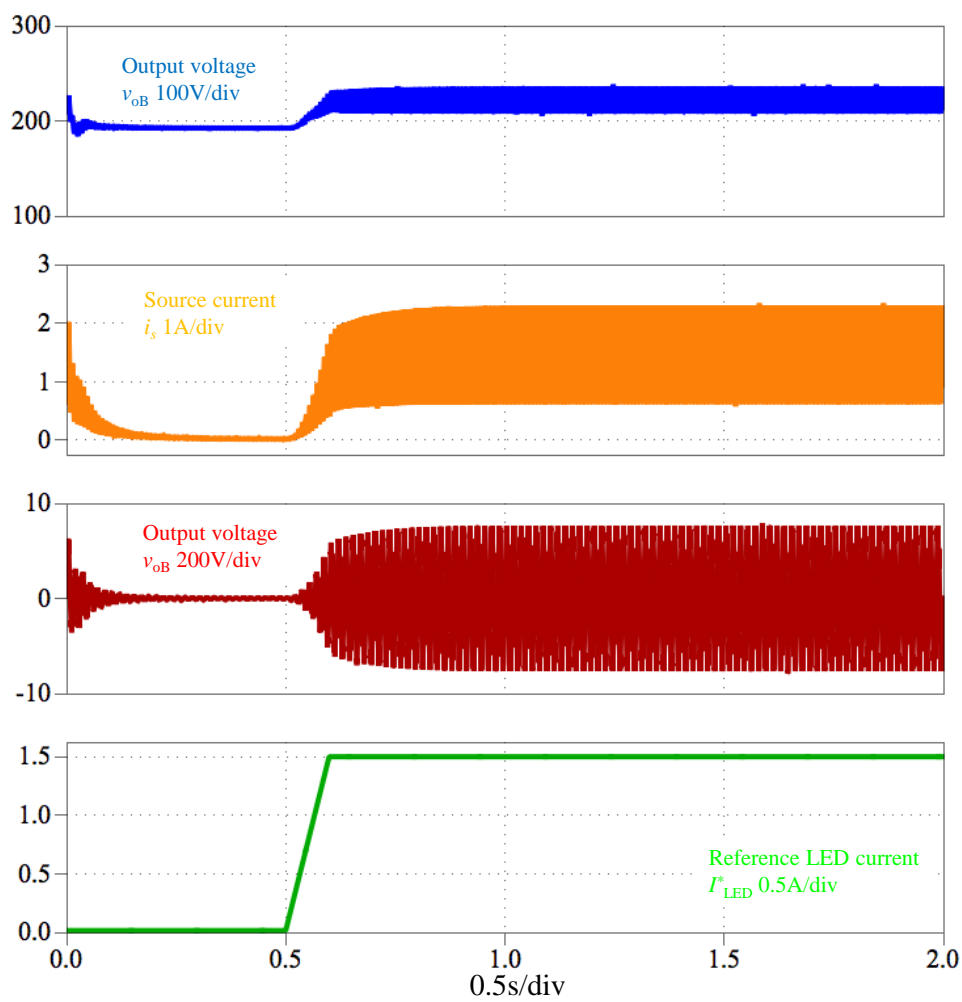

Figure 12. Simulation waveforms when the reference LED current $I_{\mathrm{LED}}^{*}$ is changed from $15 \mathrm{~mA}$ to $1.5 \mathrm{~A}$.

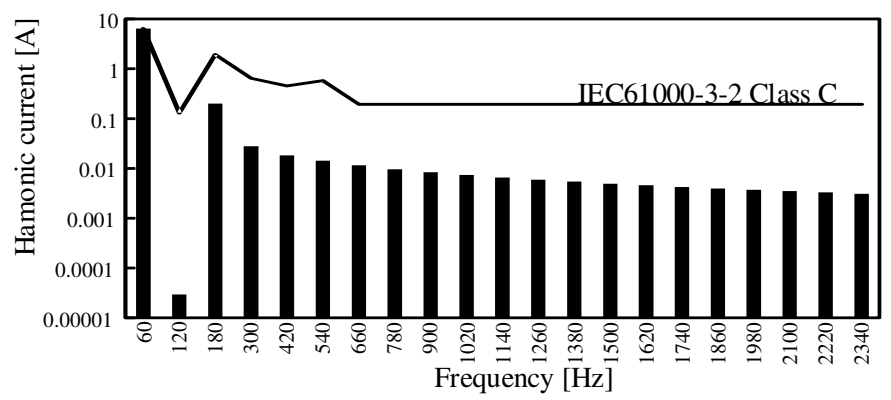

Figure 13. Fast Fourier Transform (FFT) analysis result when the average LED current is $1.5 \mathrm{~A}$. 


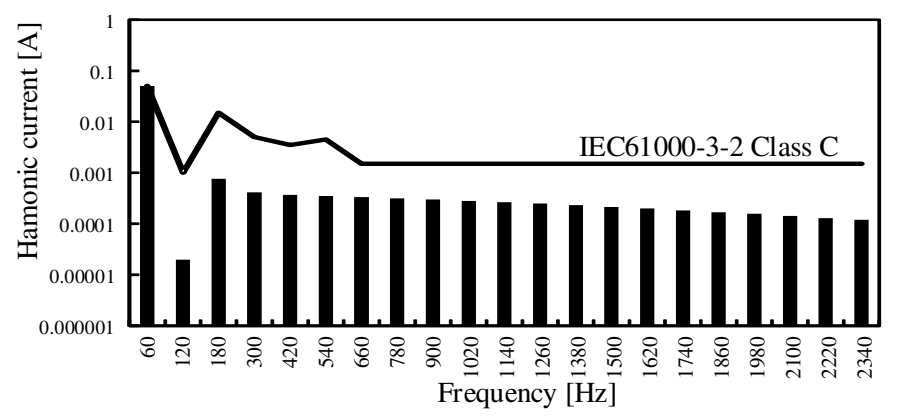

Figure 14. FFT analysis result when the average LED current is $15 \mathrm{~mA}$.

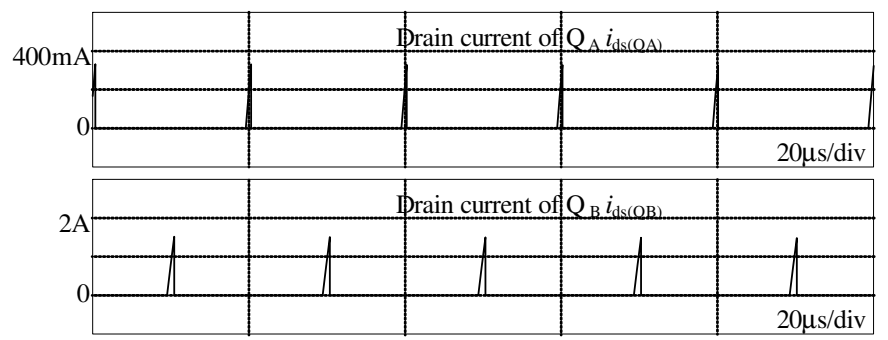

Figure 15. Simulation results of the proposed cooperative control method when the reference LED current $I_{\mathrm{LED}}^{*}$ is $15 \mathrm{~mA}$.

\section{Experimental Results}

A prototype LED driver with the proposed cooperative control method was constructed and tested. A digital controller (TMDSDOCK28035) (Texas Instruments Incorporated, Dallas, TX, USA) including a digital signal processor (DSP: TMS320F28035, $60 \mathrm{MHz}$ ) (Texas Instruments Incorporated, Dallas, TX, USA) was used in the experimental setup. Figure 16 shows the picture of the LED driver used in an experiment.

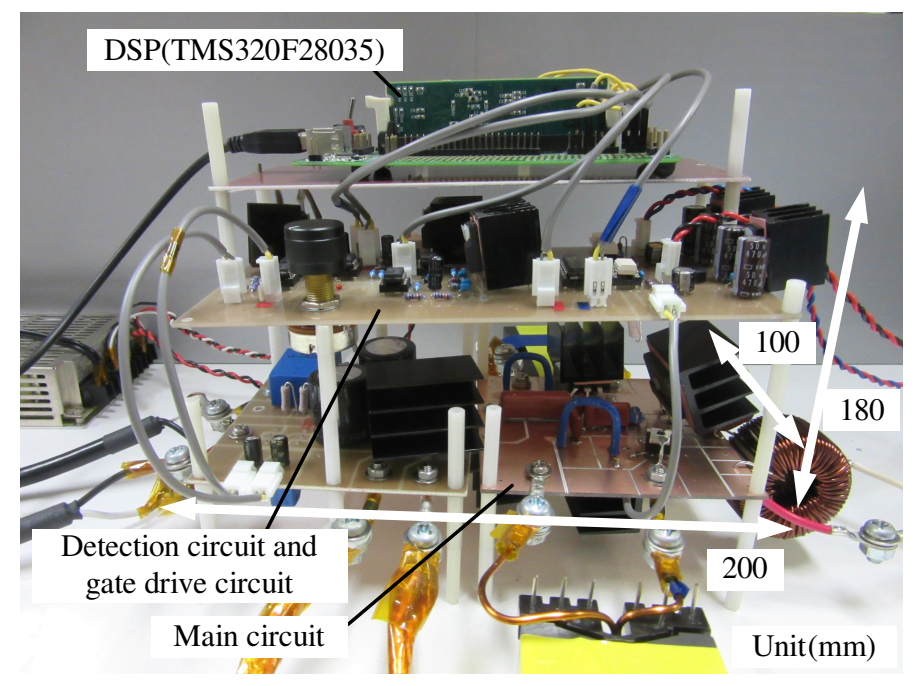

Figure 16. The picture of the LED driver used in an experiment.

Figures 17 and 18 show the experimental results of the proposed cooperative control method when the reference LED current $I_{\mathrm{LED}}^{*}$ is $1.5 \mathrm{~A}$ and $15 \mathrm{~mA} . v_{\mathrm{s}}$ is the source voltage, $i_{\mathrm{s}}$ is the source current, $V_{\mathrm{OB}}$ is the output voltage of the buck-boost chopper, and $I_{\mathrm{LED}}$ is the LED current. From Figure $17, i_{\mathrm{s}}$ is observed to be nearly sinusoidal and the power factor is 0.99 . The average LED current 
agrees with the reference LED current of 1.5 A. Although the LED current fluctuates by twice the source frequency, the LED current is always above over 5\% of the rated LED current. This means that the proposed LED driver satisfies the standard of the Electrical Appliances and Materials Safety Act in Japan.

Figures 19 and 20 show the FFT analysis results of $i_{\mathrm{s}}$. From these figures, it can be inferred that the LED driver with the proposed cooperative control method can satisfy the conditions in IEC61000-3-2.

Figure 21 shows the LED current and the output voltage of the buck-boost chopper for the reference output current $I_{\mathrm{LED}}^{*}$. In Figure 21, the red and blue dots represent the experimental results. From Figure 21, we can see that the outputs of both converters agree with the reference values.

Figure 22 shows the experimental results of the drain currents $v_{\mathrm{D}(\mathrm{QA})}$ and $v_{\mathrm{D}(\mathrm{QB})}$ at a reference LED current $I_{\mathrm{LED}}^{*} 15 \mathrm{~mA}$. From these waveforms, it can be observed that the on-intervals $T_{\mathrm{on}}(\mathrm{QA})$ and $T_{\mathrm{on}(\mathrm{QB})}$ are always more than $300 \mathrm{~ns}$.

Figure 23 shows the experimental result when the reference LED current $I_{\mathrm{LED}}^{*}$ is changed from $15 \mathrm{~mA}$ to $1.5 \mathrm{~A}$. In Figure 23, the green line is the reference voltage given for the analog channel of the DSP. When this value is $3 \mathrm{~V}$, the $I_{\mathrm{LED}}^{*}$ is $1.5 \mathrm{~A}$. From this result, $I_{\mathrm{LED}}$ agrees with $I_{\mathrm{LED}}^{*}$.

Figure 24 shows the comparison of illuminance between minimum and maximum LED currents. The proposed LED driver doesn't cause flicker for all dimming region.

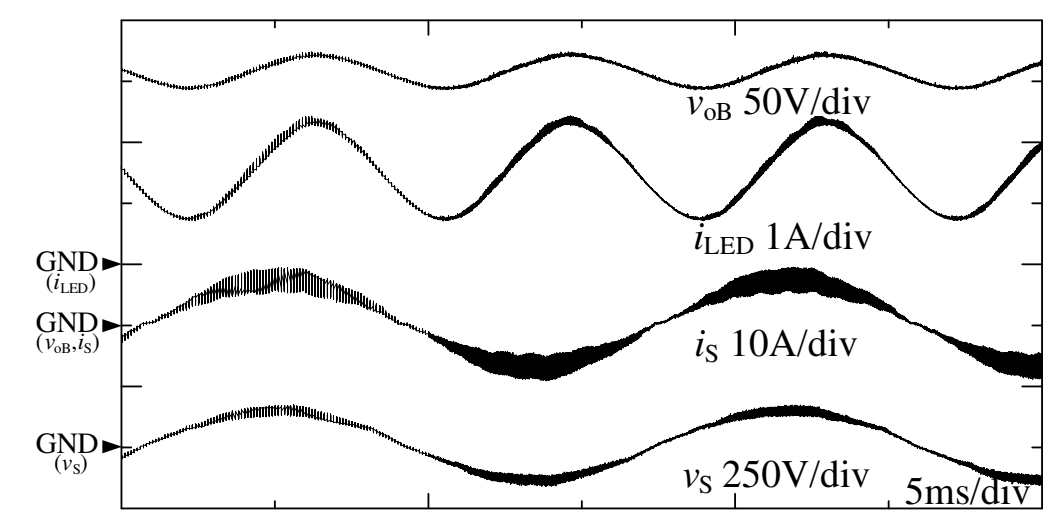

Figure 17. Experimental results of the proposed cooperative control method when the reference LED current $I_{\text {LED }}^{*}$ is $1.5 \mathrm{~A}$.

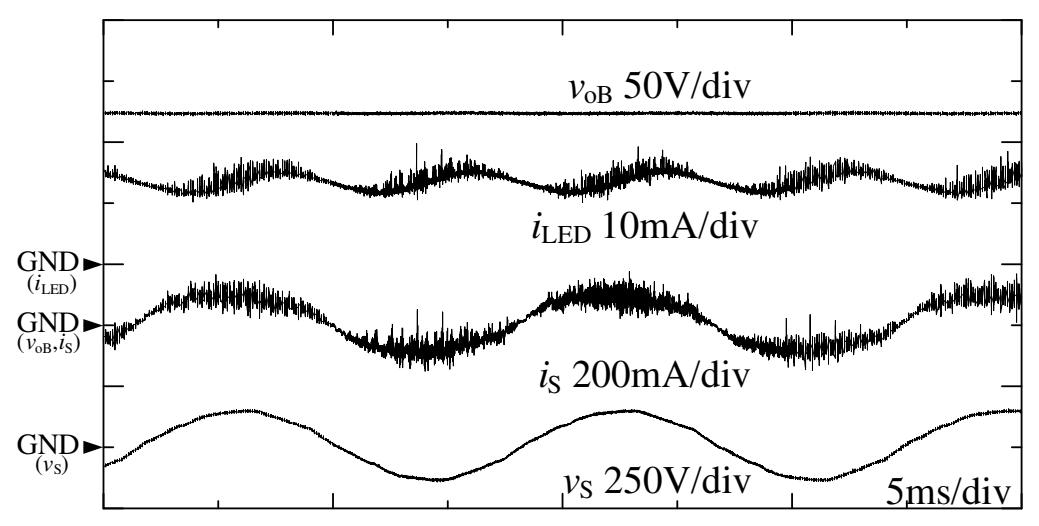

Figure 18. Experimental results of the proposed cooperative control method when the reference LED current $I_{\mathrm{LED}}^{*}$ is $15 \mathrm{~mA}$. 


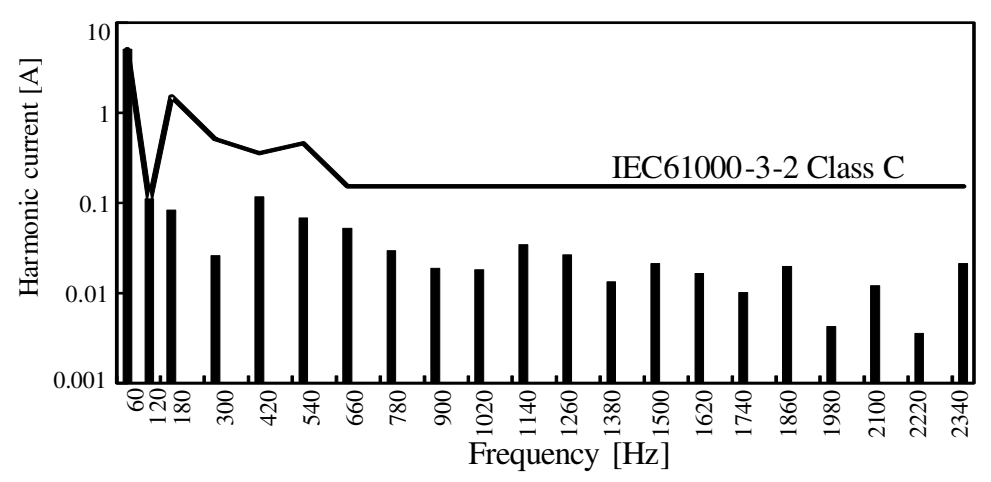

Figure 19. FFT analysis result when the average LED current is $1.5 \mathrm{~A}$.

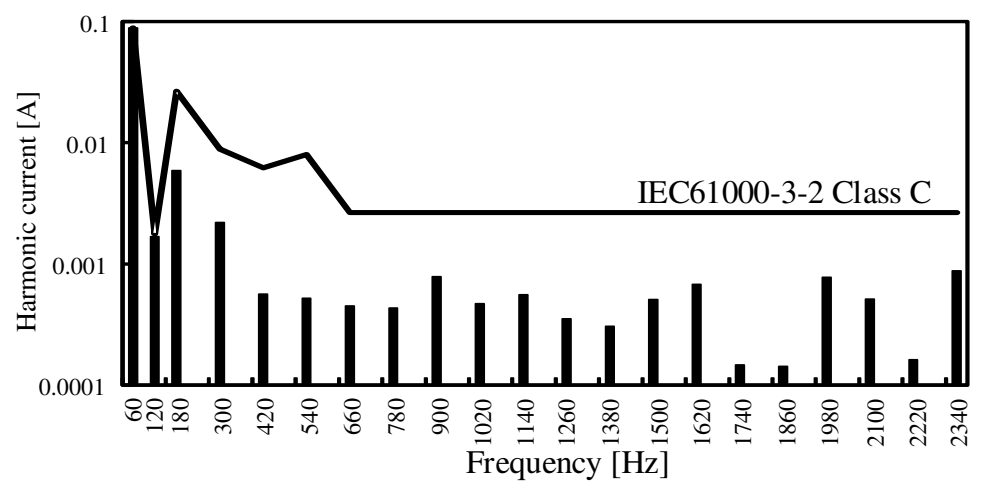

Figure 20. FFT analysis result when the average LED current is $15 \mathrm{~mA}$.

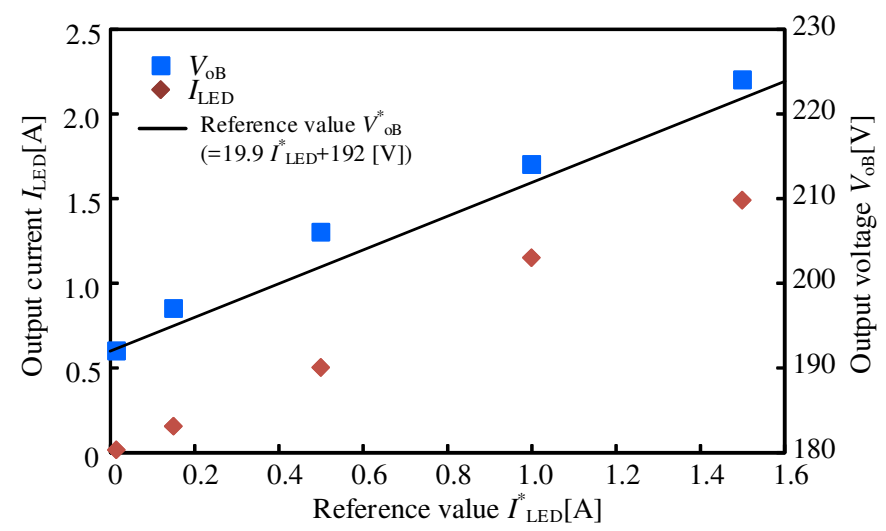

Figure 21. Experimental results of the output current $I_{\mathrm{LED}}$ and voltage $V_{\mathrm{oB}}$ for the reference LED current $I_{\text {LED }}^{*}$.

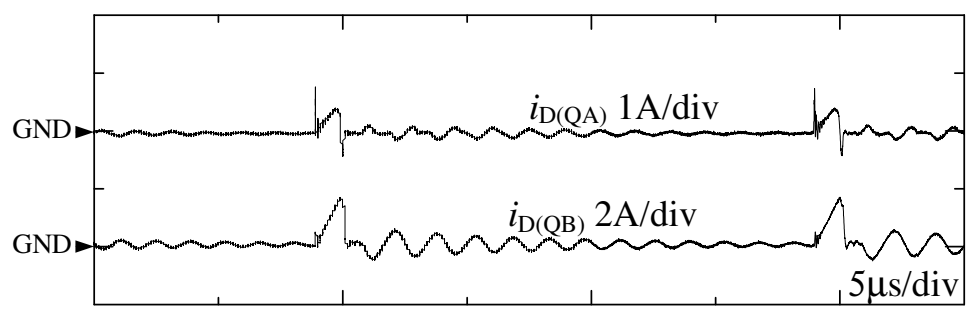

Figure 22. Experimental results of the proposed cooperative control method when the reference LED current $I_{\mathrm{LED}}^{*}$ is $15 \mathrm{~mA}$. 


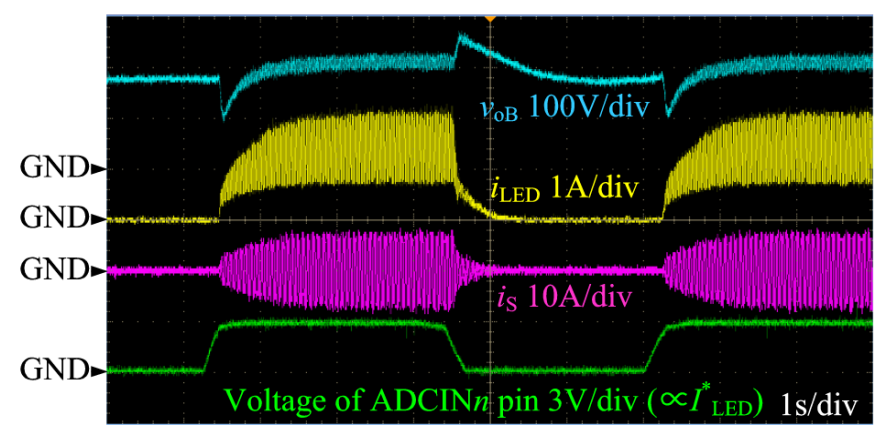

Figure 23. Experimental result when the reference LED current $I_{\text {LED }}^{*}$ is changed from $15 \mathrm{~mA}$ to $1.5 \mathrm{~A}$.

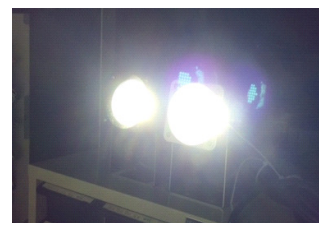

Illuminance: $16,080 \mathrm{~lx}$ LED current: $1.5 \mathrm{~A}$

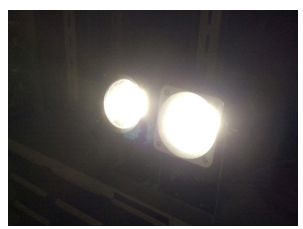

Illuminance: $257 \mathrm{~lx}$ LED current: $15 \mathrm{~mA}$

Figure 24. Comparison of illuminance between minimum and maximum LED currents.

\section{Comparison of Power Conversion Efficiency between Si- and SiC-MOSFETs}

Now, we discuss the power conversion efficiency. Figure 25 shows loss analysis of the experimental circuit when the output current is $1.5 \mathrm{~A}$. The power conversion efficiency is $90.5 \%$, and the total loss is $45.4 \mathrm{~W}$. The losses of the MOSFETs $Q_{\mathrm{A}}$ and $Q_{\mathrm{B}}$ are dominated by the conduction losses when the output power is high. When the output current is $1.5 \mathrm{~A}$, the conduction losses of $Q_{\mathrm{A}}$ and $Q_{\mathrm{B}}$ are $3.0 \mathrm{~W}$ and $3.3 \mathrm{~W}$, respectively. The losses in MOSFETs are $10.1 \mathrm{~W}$, which is $22.2 \%$ of the total loss. Thus, it is verified that reducing the conduction losses helps improve the power conversion efficiency of the experimental circuit.

$\mathrm{SiC}$ offers a low on-state resistance for purposes reducing the conduction loss. We use the SiC-MOSFETs C3M0065090J and C2M0040120D for $Q_{\mathrm{A}}$ and $Q_{\mathrm{B}}$, respectively.

Table 2 shows Si- and SiC-MOSFET Parameters in the experimental setup. From Table 2, the drainsource on-state resistance of $Q_{\mathrm{A}}$ and $Q_{\mathrm{B}}$ are reduced about $77 \%$ and $40 \%$ by replacing Si-MOSFETs with SiC-MOSFETs.

Figure 26 shows loss analysis of the experimental circuit when the output current is $1.5 \mathrm{~A}$. When the output current was $1.5 \mathrm{~A}$, the conduction losses of $Q_{\mathrm{A}}$ and $Q_{\mathrm{B}}$ are $0.76 \mathrm{~W}$ and $1.15 \mathrm{~W}$, respectively. The the conduction losses are reduced by $74.8 \%$ and $42.8 \%$, respectively. By replacing the Si-MOSFETs with SiC-MOSFETs, the power conversion efficiency was improved by $0.9 \%$. Figure 27 shows experimental results of the power conversion efficiency. From this result, the power conversion efficiency of the SiC-MOSFETs-based proposed LED driver is higher than that of the Si-MOSFETs-based proposed LED driver over the whole region.

Table 3 shows the comparison result between the conventional and proposed methods. The proposed LED driver was tested for the source voltage 100 Vrms. However, the SiC-MOSFETs based LED driver can connect to the source voltage 300 Vrms. The proposed LED driver can control LED current linearly. In the proposed method with Si-MOSFET, the efficiency is over $90 \%$ in the range of $34 \%$ or more rated current. In the proposed method with SiC-MOSFET, the efficiency is over $90 \%$ in the range of $17 \%$ or more rated current. 


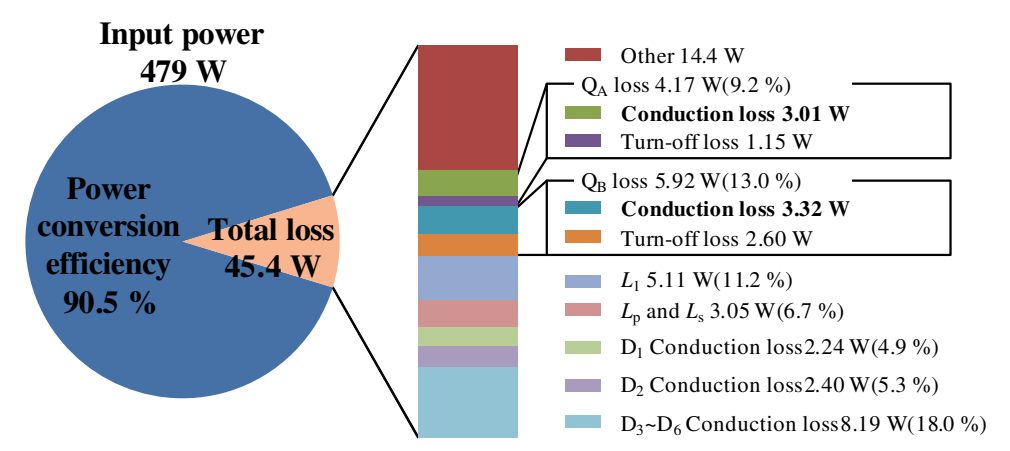

Figure 25. Loss analysis of the LED driver using Si MOSFET DC-DC converters.

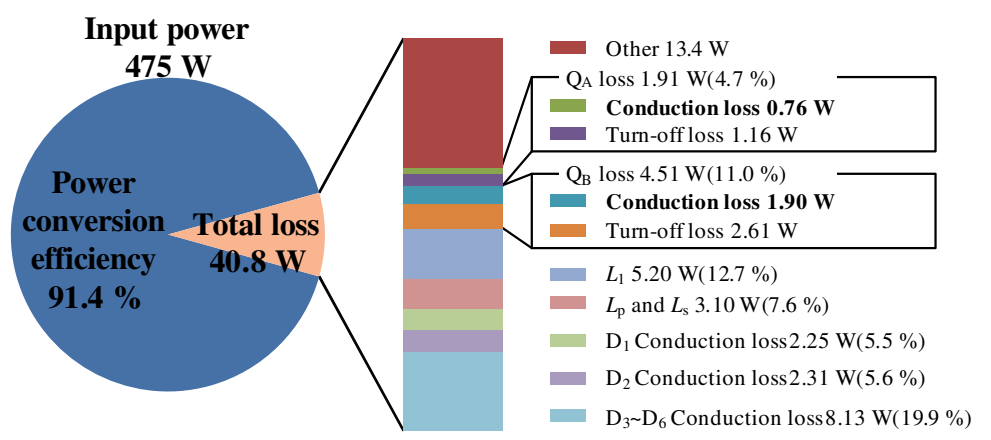

Figure 26. Loss analysis of the LED driver using SiC MOSFET DC-DC converters.

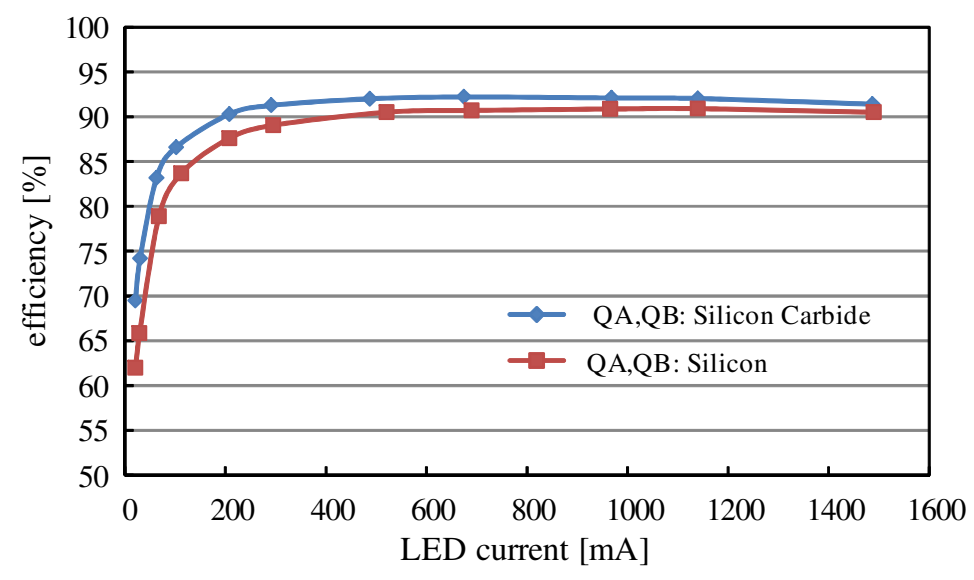

Figure 27. Experimental results of the efficiency for the output current $I_{\mathrm{LED}}$.

We discuss about the heat sink of the MOSFET $Q_{\mathrm{A}}$ and $Q_{\mathrm{B}}$.

The thermal resistance of the heat sink $R t h_{\mathrm{h}-\mathrm{a}}$ can be expressed by:

$$
R t h_{\mathrm{h}-\mathrm{a}}=\frac{T_{\mathrm{j}}-T_{\mathrm{a}}}{P_{\text {loss }}}-R t h_{\mathrm{j}-\mathrm{p}}-R t h_{\mathrm{p}-\mathrm{h}}
$$

where $T_{\mathrm{j}}$ is the device junction temperature, $T_{\mathrm{a}}$ is ambient temperature, $P_{\text {loss }}$ is the loss of the MOSFET, $R t h_{\mathrm{j}-\mathrm{p}}$ is the thermal resistance from the device junction to the package surface and $R t h_{\mathrm{p}-\mathrm{h}}$ is the thermal resistance from the package surface to the heat sink.

Figure 28 shows the outline drawing of the heat sink that has six fins. The width and length of the heat sink are determined according to the TO-220 package size. The surface area of the heat sink $S_{\mathrm{h}}$ can be expressed by: 


$$
S_{\mathrm{h}}=6 \times 2 \times 0.025 \times H \times 10^{-3} .
$$

In addition, $R t h_{\mathrm{h}-\mathrm{a}}$ can be expressed with $S_{\mathrm{h}}$ by:

$$
R t h_{\mathrm{h}-\mathrm{a}}=\frac{1}{h S_{\mathrm{h}}},
$$

where $h$ is the heat transfer coefficient of the heat sink. To estimate the height of the heat sink $H$, it is assumed that $R t h_{\mathrm{j}-\mathrm{p}}$ is $5^{\circ} \mathrm{C} / \mathrm{W}$ and $R t h_{\mathrm{p}-\mathrm{h}}$ is $1^{\circ} \mathrm{C} / \mathrm{W}, h$ is $5 \mathrm{~W} / \mathrm{m}^{2}{ }^{\circ} \mathrm{C}$. From Equations (15)-(17), if $T_{\mathrm{j}}$ is $150{ }^{\circ} \mathrm{C}$ and $T_{\mathrm{a}}$ is $50^{\circ} \mathrm{C}, \mathrm{H}$ can be expressed by:

$$
H=\frac{10^{3}}{1.5\left(\frac{100}{P_{\text {loss }}}-6\right)} .
$$

\begin{tabular}{|c|c|c|c|c|c|}
\hline \multirow{2}{*}{\multicolumn{2}{|c|}{ Parameter }} & \multicolumn{2}{|c|}{$Q_{\mathrm{A}}$} & \multicolumn{2}{|c|}{$Q_{\text {B }}$} \\
\hline & & $\begin{array}{c}\text { (SiC-MOSFET) } \\
\text { C3M0065090J }\end{array}$ & $\begin{array}{l}\text { (Si-MOSFET) } \\
\text { STF20NM65N }\end{array}$ & $\begin{array}{l}\text { (SiC-MOSFET) } \\
\text { C2M0040120D }\end{array}$ & $\begin{array}{c}\text { (Si-MOSFET) } \\
\text { TK40J60T }\end{array}$ \\
\hline \multicolumn{2}{|c|}{ Drain-source voltage $V_{\mathrm{DS}}(\mathrm{V})$} & 900 & 650 & 1200 & 600 \\
\hline \multicolumn{2}{|c|}{ Gate-source voltage $V_{\mathrm{GS}}(\mathrm{V})$} & $-8 / 19$ & $-25 / 25$ & $-10 / 25$ & $-30 / 30$ \\
\hline \multirow{2}{*}{$\begin{array}{c}\text { Continuous } \\
\text { drain current }(\mathrm{A})\end{array}$} & $T_{\mathrm{C}}=25^{\circ} \mathrm{C}$ & 35 & 15 & 40 & 40 \\
\hline & $T_{\mathrm{C}}=100^{\circ} \mathrm{C}$ & 22 & 9.45 & 60 & - \\
\hline \multicolumn{2}{|c|}{ Junction temperature $T_{\mathrm{j}}\left({ }^{\circ} \mathrm{C}\right)$} & -55 to 150 & -55 to 150 & -55 to 150 & -55 to 150 \\
\hline \multirow{2}{*}{$\begin{array}{c}\text { Drain-source } \\
\text { on-state resistance }(\mathrm{m} \Omega)\end{array}$} & $T_{\mathrm{C}}=25^{\circ} \mathrm{C}$ & 65 & 250 & 40 & 68 \\
\hline & $T_{\mathrm{C}}=100^{\circ} \mathrm{C}$ & 78 & 270 & 52 & 80 \\
\hline \multicolumn{2}{|c|}{ Input capacitance $C_{\mathrm{iss}}(\mathrm{pF})$} & 660 & 1280 & 1893 & 3900 \\
\hline \multicolumn{2}{|c|}{ Output capacitance $C_{\mathrm{oss}}(\mathrm{pF})$} & 60 & 110 & 150 & 9200 \\
\hline \multicolumn{2}{|c|}{ Reverse capacitance $C_{\mathrm{rss}}(\mathrm{pF})$} & 4.0 & 10 & 10 & 280 \\
\hline
\end{tabular}

Table 2. Si- and SiC-metal-oxide-semiconductor field-effect transistors (MOSFETs) parameters in the experimental setup.

Table 3. Comparison between the conventional and proposed methods.

\begin{tabular}{cccc}
\hline Item & Conventional Method & $\begin{array}{c}\text { Proposed Method } \\
\text { with Si-MOSFETs }\end{array}$ & $\begin{array}{c}\text { Proposed Method } \\
\text { with SiC-MOSFETs }\end{array}$ \\
\hline AC input voltage & $185-265 \mathrm{Vrms}$ & $100 \mathrm{Vrms}$ & $100 \mathrm{Vrms}$ \\
Output power & $210 \mathrm{~W}$ & $408 \mathrm{~W}$ & $408 \mathrm{~W}$ \\
Dimming type & Step & Linear & Linear \\
Dimming range (\%) & $50,75,100$ & $1-100$ & $1-100$ \\
Efficiency at maximum output power & $92.1 \%$ & $90.5 \%$ & $91.4 \%$ \\
Efficiency at minimum output power & $90.7 \%$ & $62.0 \%$ & $69.5 \%$ \\
Minimum illuminance of LEDs & $1680 \mathrm{~lx}$ & $257 \mathrm{~lx}$ & $257 \mathrm{~lx}$ \\
\hline
\end{tabular}

Table 4 shows the estimation of the heat sink size. From Table 4 , the heat sink volume of $Q_{\mathrm{A}}$ and $Q_{\mathrm{B}}$ is reduced $61 \%$ and $32 \%$ by replacing the Si MOSFET with SiC MOFET. In this paper, all converters are driven in the discontinuous mode (DCM). However, in order to further improve the efficiency, it is also possible to consider critical conduction mode (CRM). 
Table 4. Estimation of the heat sink size.

\begin{tabular}{ccccc}
\hline & \multicolumn{2}{c}{$\mathbf{Q}_{\mathbf{A}}$} & \multicolumn{2}{c}{$\mathbf{Q}_{\mathbf{B}}$} \\
\hline Item & Si-MOSFET & SiC-MOSFET & Si-MOSFET & SiC-MOSFET \\
Loss & $4.17 \mathrm{~W}$ & $1.91 \mathrm{~W}$ & $5.92 \mathrm{~W}$ & $4.51 \mathrm{~W}$ \\
Height of the heat sink & $37 \mathrm{~mm}$ & $14.4 \mathrm{~mm}$ & $61.2 \mathrm{~mm}$ & $41.2 \mathrm{~mm}$ \\
\hline
\end{tabular}

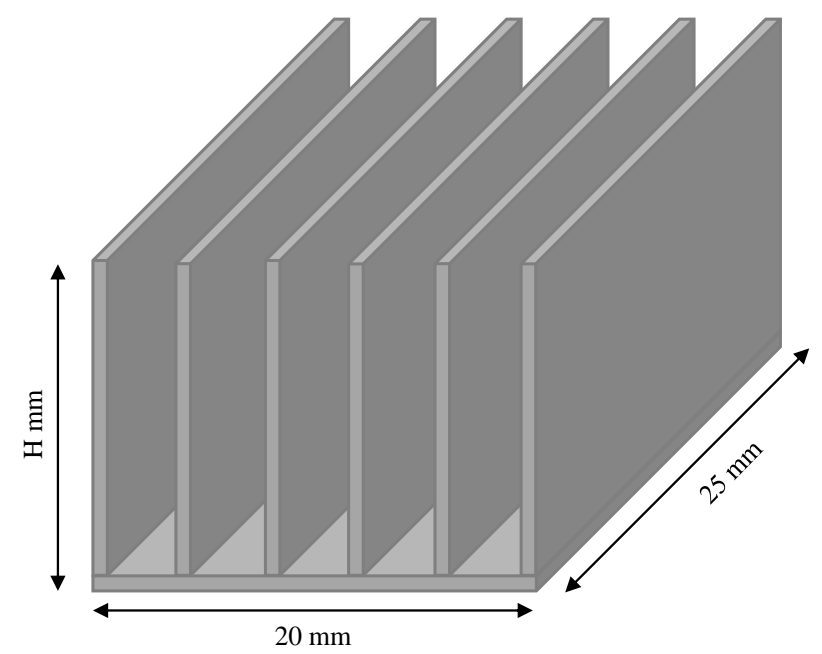

Figure 28. Outline drawing of the heat sink.

\section{Improvement of Power Conversion Efficiency for Low LED Current Region}

The power conversion efficiency of the proposed LED driver is low for the low LED current region. The loss of the MOSFET $Q_{\mathrm{B}}$ is dominated by the turn-off loss when the output power is low. In addition, the turn-off loss of $Q_{\mathrm{B}}$ can be expressed by:

$$
P_{\mathrm{S}_{-} \mathrm{Q}_{\mathrm{B}}}=f_{\mathrm{sW}} \int_{t_{0}}^{t_{0}+\Delta T_{\text {off }}} v_{\mathrm{DS}\left(\mathrm{Q}_{\mathrm{B}}\right)} i_{\mathrm{D}\left(\mathrm{Q}_{\mathrm{B}}\right)} d t,
$$

where $f_{\mathrm{sw}}$ is the switching frequency, $t_{0}$ is the start time of $Q_{\mathrm{B}}$ turn-off period and $\Delta T_{\text {off }}$ is the $Q_{\mathrm{B}}$ turn-off period. From Equation (19), the turn-off loss depends on the switching frequency and the turn-off loss is reduced by lowering the switching frequency.

Figure 29 shows a control block of the proposed cooperative control method with variable switching frequency. We added the variable switching frequency function to the proposed control block. This function has hysteresis characteristics with $I_{\text {LED }}^{*}$. Figure 30 shows the relationship between the LED reference current and the switching frequency. In addition, the hysteresis characteristics can be expressed by:

$$
\left\{\begin{array}{l}
I_{\mathrm{LED}}^{*} \geq I_{(\text {upper limit })} \rightarrow f_{\mathrm{sw}}=50 \mathrm{kHz}, \\
I_{\mathrm{LED}}^{*} \leq I_{(\text {lower limit })} \rightarrow f_{\mathrm{sw}}=25 \mathrm{kHz} .
\end{array}\right.
$$

We determined $I_{(\text {upper limit) }}$ and $I_{(\text {lower limit) }}$ by comparing the experimental result of the efficiency with the switching frequency as $25 \mathrm{kHz}$ and $50 \mathrm{kHz}$.

Figure 31 shows the experimental result of the efficiency with the switching frequency as $25 \mathrm{kHz}$ and $50 \mathrm{kHz}$. In Figure 31, Si MOSFETs are used for the proposed LED driver. When the output current is smaller than $250 \mathrm{~mA}$, the power conversion efficiency of the switching frequency $25 \mathrm{kHz}$ is higher than that of the switching frequency $50 \mathrm{kHz}$. Therefore, we decided that $I_{\text {(upper limit) }}$ is $300 \mathrm{~mA}$ and $I_{(\text {lower limit) }}$ is $200 \mathrm{~mA}$. As a result, when the output current is $15 \mathrm{~mA}$, the power conversion efficiency is improved by about $5 \%$. 


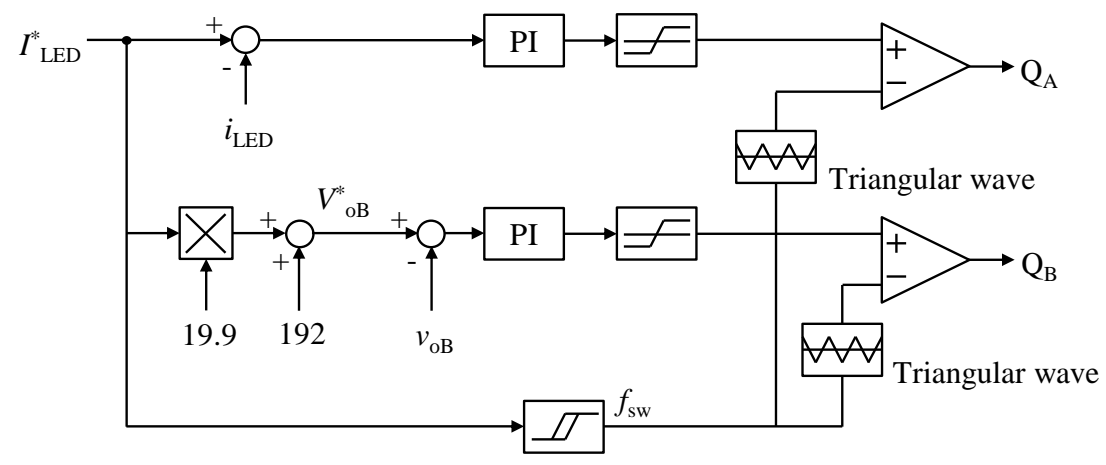

Figure 29. Control block of the proposed cooperative control method with variable switching frequency.

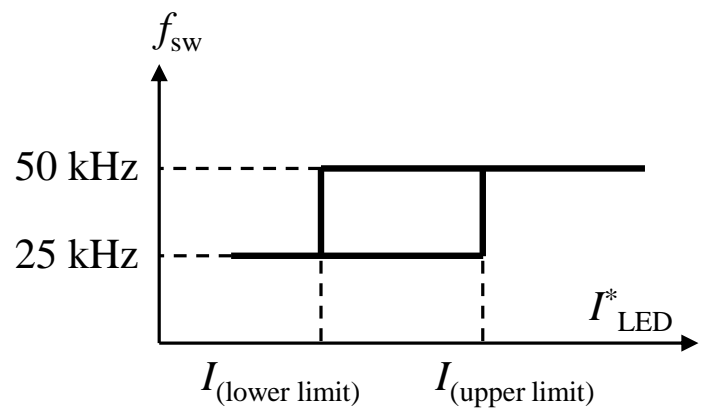

Figure 30. Relationship between the LED reference current and the switching frequency.

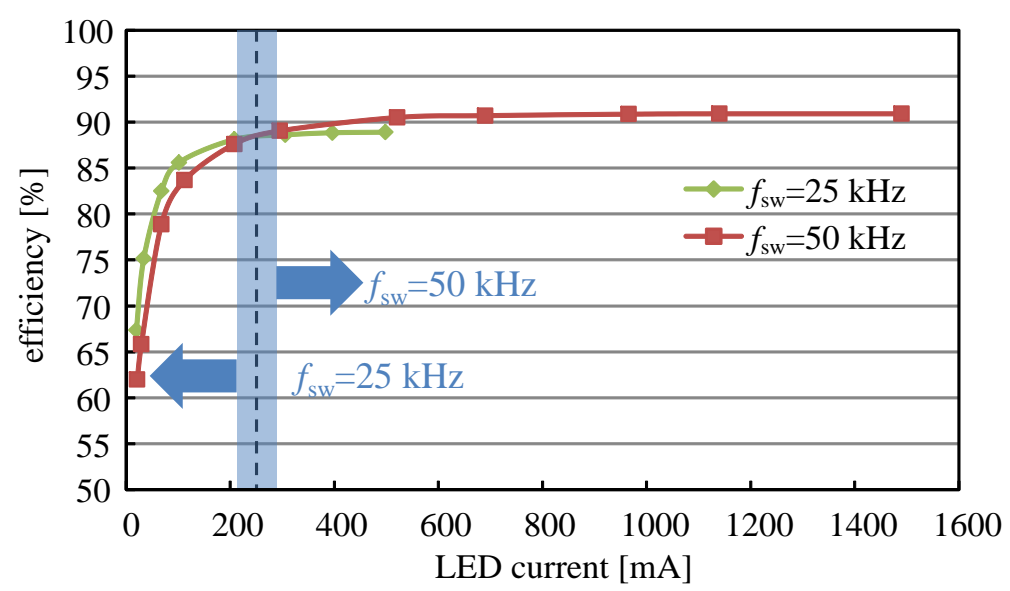

Figure 31. Experimental results of the efficiency with the switching frequency as $25 \mathrm{kHz}$ and $50 \mathrm{kHz}$.

\section{Conclusions}

This paper described the design and experimental verification of 400-W class LED driver with cooperative control method for two-parallel connected DC/DC converters. This proposed cooperative control method drove two DC/DC converters, based on the reference LED current. All converters operated in the DCM to improve the power factor using simple controllers. In this paper, the circuit parameters were designed for DCM and for the stable on-intervals of switching devices. A prototype LED driver using the proposed cooperative control method was built and tested. From the simulation and experimental results, the on-intervals of the MOSFETs were observed to be higher than $300 \mathrm{~ns}$ under dimming operation from $1 \%$ to $100 \%$, by using the cooperative control method. The proposed LED driver reduced the minimum LED current by $90.7 \%$, compared to the conventional control method. From simulation and experimental results, the linear dimming of the proposed LED driver achieved stable operation when the reference LED current was changed from $1 \%$ to $100 \%$. The maximum power 
conversion efficiency by using SiC-MOSFETs based LED driver is $91.4 \%$. Finally, the variable switching frequency method is proposed for improving the power conversion efficiency for low LED current region. Experimental results revealed that the power conversion efficiency can be improved for the low LED current region. Dynamic analysis was not conducted in this paper. In a future work, it would be important to examine the system for its stability.

Author Contributions: T.Y. significantly contributed to the design of the proposed LED driver and the implementation of the computer simulation. Y.K. contributed the fabrication of the experimental setup and it's evaluation. H.Y. proposed the basic control topology and helped with the writing of this paper. T.T., M.O. and T.H. were responsible for guidance and key suggestions.

Funding: This research received no external funding.

Conflicts of Interest: The authors declare no conflict of interest.

\section{Abbreviations}

The following abbreviations are used in this manuscript:

$\begin{array}{ll}\text { LED } & \text { Light-emitting diode } \\ \text { DCM } & \text { Discontinuous conduction mode } \\ \text { THD } & \text { Total harmonic distortion } \\ \text { MOSFET } & \text { Metal-oxide-semiconductor field-effect transistor } \\ \text { PFC } & \text { Power factor correction } \\ \text { FFT } & \text { Fast Fourier Transform } \\ \text { DSP } & \text { Digital signal processor }\end{array}$

\section{References}

1. International Energy Agency. Energy Matters. Available online: https://www.iea.org/publications/ freepublications/publication/EnergyMattersBrochure.2.pdf (accessed on 25 July 2016).

2. United Nations Environment. Minamata Convention on Mercury. Available online: http: //www.unep.org/hazardoussubstances/Portals/9/Mercury/Documents/dipcon/CONF3Minamata\% 20Convention\%20on\%20Mercuryfinal\%2026\%2008e.pdf (accessed on 25 July 2016).

3. Schratz, M.; Gupta, C.; Struhs, T.J.; Gray, K. Improving light quality with cost-effective LED technology. IEEE Ind. Appl. Mag. 2016, 22, 55-62. [CrossRef]

4. Lee, J.-Y.; Moon, G.-W.; Park, H.-J.; Youn, M.-J. Integrated ZCS Quasi-Resonant Power Factor Correction Converter Based on Flyback Topology. IEEE Trans. Power Electron. 2000, 15, 634-643.

5. Arias, M.; Lamar, D.G.; Linera, F.F.; Balocco, D.; Diallo, A.A.; Sebastian, J. Design of a Soft-Switching Asymmetrical Half-Bridge Converter as Second Stage of an LED Driver for Street Lighting Application. IEEE Trans. Power Electron. 2012, 27, 1608-1621. [CrossRef]

6. Xie, X.; Li, J.; Peng, K.; Xhao, C.; Lu, Q. Study on the Single-Stage Forward-Flyback PFC Converter with QR Control. IEEE Trans. Power Electron. 2016, 31, 430-442. [CrossRef]

7. Cheng, C.-A.; Cheng, H.-L.; Chung, T.-Y. A Novel Single-Stage High-Power-Factor LED Street-Lighting Driver With Coupled Inductors. IEEE Trans. Ind. Appl. 2014, 50, 3037-3045. [CrossRef]

8. Cheng, C.-A.; Chang, C.-H.; Chung, T.-Y.; Yang, F.-L. Design and Implementation of a Single-Stage Driver for Supplying an LED Street-Lighting Module With Power Factor Corrections. IEEE Trans. Power Electron. 2015, 30, 956-966. [CrossRef]

9. Moo, C.-S.; Chen, Y.-J.; Yang, W.-C. An Efficient Driver for Dimmable LED Lighting. IEEE Trans. Power Electron. 2012, 27, 4613-4618. [CrossRef]

10. Jane, G.; Su, C.-C.; Chiu, H.-J.; Lo, Y.-K. High-Efficiency LED Driver for Street Light Applications. In Proceedings of the International Conference on Renewable Energy Research and Applications (ICRERA), Nagasaki, Japan, 11-14 November 2012; pp. 105-107.

11. Yada, T.; Yamada, H.; Hanamoto, T. A Novel Cooperational Control Method for LED Driver with Parallel Flyback Converter. J. Jpn. Inst. Power Electron. 2015, 40, JIPE-40-19. 
12. Katamoto, Y.; Yamada, H.; Tanaka, T.; Okamoto, M.; Yada, T. Experimental Verification of Cooperative Control Method for 400-W Class LED Drivfer With Wide Dimming Range. In Proceedings of the 19th International Conference on Electrical Machines and Systems, Chiba, Japan, 13-16 November 2016; p. DS4G-2-8.

13. Ministry of Economy, Trade, and Industry. Electrical Appliances and Materials Safety Act; Ministry of Economy, Trade and Industry: Chiyoda, Japan, 2018. 